\title{
Validity and reliability of medication adherence scale in FMF (adult version)
}

\author{
Berna Eren Fidanci ${ }^{1 *}$, Sirzat Yesilkaya ${ }^{1}$, Cengizhan Acikel ${ }^{1}$, Aslan Ozden', Dogan Simsek', Fatih Yildiz², \\ Turkish FMF Study Group, Bunyamin Kisacik², Mehmet Sayarlıoglu², Servet Akar², Soner Senel' ${ }^{2}$, Mehmet Tunca², \\ Sule Yavuz ${ }^{2}$, Abdurrahman Tufan², Afig Berdeli ${ }^{2}$, Ahmet Onat ${ }^{2}$, Ahmet Gul², Berna Goker', Timucin Kasifoglu², \\ Haner Direskeneli², Sukran Erten², Gul Ozcelik', Faysal Gok1, Seza Ozen', Erkan Demirkaya ${ }^{1}$
}

From 21st European Pediatric Rheumatology (PReS) Congress

Belgrade, Serbia. 17-21 September 2014

\section{Introduction}

MASIF (Medication Adherence Scale in FMF) is an instrument designed to measure adherence to treatment in children with Familial Mediterranean Fever (FMF). We have developed this scale for children with FMF and found valid and reliable.

\section{Objectives}

In this study, it was aimed to assess the validity and reliability of this adherence scale for medical treatment in adult FMF patients.

\section{Methods}

This study is multicentre and 14 centers participated to the study. Patients with FMF using medication at least for 6 months and accepted to participate constituted the sample of the study. Besides "Medication Adherence Scale in FMF Patients (MASIF)", "Data collection forms about the sociodemographic and medical information (demographic, clinical and laboratory findings) of patients", and "Morisky Medication Adherence Scale (MMAS)" were used as data collection instruments.

\section{Results}

There were 133 patients with FMF enrolled for the validation of the study. The median age of the patients $(\mathrm{n}=133)$ was 28.60 years (min.18.12-max.71.34) and $52.6 \%$ of them were female. The median number of the attack frequency was 13.50 (min. 0 -max 99) in a year and $57.9 \%$ of the participants had irregular attacks. For internal consistency,

${ }^{1}$ FAVOR, FMF Arthritis Vasculitis and Orphan Disease Research in Paediatric Rheumatology, Ankara, Turkey

Full list of author information is available at the end of the article
Cronbach's alpha was 0,764 for MASIF adult version. Also, there was a positive and significant correlation between test and retest score $(\mathrm{t}=0.971 ; \mathrm{p}=0.340)$. Morisky was used as gold standard. For the "criterion validity" the correlation with Morisky and MASIF was evaluated $(\mathrm{r}=0.530, \mathrm{p}=0.000)$ and for the "structure" validity, factor analyzes and Kaiser-Meyer-Olkin tests were performed.

\section{Conclusion}

Approximately $10-15 \%$ of patients with FMF are nonresponders but it was claimed that in fact they are noncompliers that causes these patients receive unnecessary biologic agent treatment procedures, which are hazardous as well as expensive. This scale will provide assessment and follow up of adherence to treatment patients and determine whether the patient is non-responders or noncompliers. It may help to determine the non-compliance and prevent unnecessary and expensive biologic agents.

\section{Disclosure of interest}

None declared.

\section{Authors' details}

${ }^{1}$ FAVOR, FMF Arthritis Vasculitis and Orphan Disease Research in Paediatric Rheumatology, Ankara, Turkey. ${ }^{2}$ Turkish FMF Study Group, ANKARA, Turkey.

Published: 17 September 2014

doi:10.1186/1546-0096-12-S1-P243

Cite this article as: Fidanci et al: Validity and reliability of medication adherence scale in FMF (adult version). Pediatric Rheumatology 2014 12(Suppl 1):P243. 